\title{
Caracterização e avaliação de processos de seleção de resíduos sólidos urbanos por meio da técnica de mapeamento
}

\author{
Characterization and evaluation of selection processes of urban \\ solid waste through mapping technique
}

\author{
Kelly Carla Dias Lobato \\ Aluna de Graduação em Engenharia de Produção Mecânica. Bolsista de Iniciação Científica em Gestão da Produção da Universidade Federal de Itajubá (UNIFEI) \\ Josiane Palma Lima \\ Engenheira Civil. Doutora pelo Departamento de Transportes da Escola de Engenharia de São Carlos da Universidade de São Paulo (USP-EESC). \\ Professora Adjunta e Pesquisadora do Instituto de Engenharia de Produção e Gestão da UNIFEI
}

\begin{abstract}
Resumo
Este trabalho apresenta os resultados da aplicação da técnica de mapeamento para a caracterização e avaliação dos processos de seleção de resíduos sólidos urbanos (RSU) desenvolvidos nas instalações de uma associação de catadores de materiais recicláveis. O trabalho utiliza métodos qualitativos por meio da pesquisa bibliográfica e estudo de caso. O levantamento de dados contou com observação, entrevista e questionário. Dentre as técnicas disponíveis para o mapeamento, foram utilizados o SIPOC, o mapa de processo e o mapofluxograma. O mapeamento de processos como ferramenta gerencial possibilitou a visualização dos processos em diferentes escalas, o relacionamento entre as atividades e o cruzamento de fluxo (transporte) dentro do galpão, sendo esse um dos principais gargalos de produção.
\end{abstract}

Palavras-chave: resíduos sólidos urbanos; materiais recicláveis; mapeamento de processos

\section{Abstract}

The objective of this work was to present the application of the mapping technique for characterization and evaluation of procedures for selection of urban solid waste (USW) developed in an association of recyclable materials collectors. This work use qualitative methods through bibliographic research and case study. The gathering of data was performed by observation, interviews and questionnaire. Amongst the techniques available for the mapping, SIPOC, process map and flowchart map were used. The process mapping as a management tool made possible the visualization of the processes in different scales, the relationship between the activities and the flow crossing (transportation) in the deposits, one of the main bottlenecks of production.

Keywords: urban solid waste; recyclable materials; process mapping.

\section{Introdução}

Atrelado ao desenvolvimento econômico está o aumento do poder de compra dos indivíduos. Devido a essa maior capacidade para o consumo, a população está se acostumando a comprar além do que será consumido e, desse modo, aumentando as estatísticas referentes à geração de resíduos sólidos urbanos.

No Brasil, a população de 187 milhões de habitantes (IBGE, 2008) gera diariamente $1,1 \mathrm{~kg}$ de resíduos sólidos urbanos por pessoa, totalizando 61,5 milhões de toneladas/ano. Apenas 39\% desses resíduos são destinados de forma adequada, ou seja, aterros controlados ou usinas de reciclagem. As regiões Norte e Nordeste apresentam as situações mais críticas, com apenas 15\% dos resíduos sólidos dispostos em aterros sanitários e 25\% dos resíduos destinados à reciclagem (ABRELPE, 2007).

Diante do aumento de produção dos resíduos sólidos urbanos, países do mundo inteiro vêm se reunindo em diversos encontros a fim de buscar soluções para esse problema. Em 1992, as diretrizes da Agenda 21 Brasileira indicaram como estratégias para o gerenciamento adequado dos resíduos sólidos a minimização da produção de resíduos, a maximização de práticas de reutilização e reciclagem ambientalmente 
corretas, a promoção de sistemas de tratamento e disposição de resíduos compatíveis com a preservação ambiental e a extensão de cobertura dos serviços de coleta e destino final (SATO; SANTOS, 1996).

Nesse aspecto, um sistema de coleta adequado é um ponto chave para fazer o retorno do material a um novo processo de produção por meio da sua reciclagem ou reutilização, desenvolvendo o que podemos chamar de cadeia produtiva reversa sustentável. Para que isso ocorra, se faz necessária a existência de uma rede sustentável de reciclagem em nível municipal e/ou regional, envolvendo atores que participam das atividades de coleta, seleção e destino final, sendo este o fator primário para a sua organização (KIPPER; MÄHLMANN, 2009).

Aproveitando essa brecha de mercado, os catadores de material reciclável organizados em associações têm reaproveitado cada vez mais os materiais descartados para fabricação de novos produtos, por meio dos processos de reciclagem, o que pode representar economia de matéria-prima, de energia fornecida pela natureza e ainda, geração de renda (RODRIGUES; CAVINATTO, 2003). Porém, o gerenciamento do material coletado e separado nos depósitos dessas associações ainda é algo que quase não acontece, sendo um desafio que pode trazer muitos benefícios tanto para aqueles que dependem da coleta para sobreviver, quanto para os organismos que investem recursos para o desenvolvimento das atividades de seleção e destino dos resíduos sólidos urbanos (OLIVEIRA; LIMA; LIMA, 2009).

As associações de catadores de materiais recicláveis sobrevivem da coleta de materiais recicláveis e separação de acordo com o tipo (tipos de plástico, papel, papelão, alumínio, vidro, entre outros) e com a cor, o que permite agregar valor antes da venda para grandes depósitos e empresas de reciclagem. De acordo com Parreira, Oliveira e Lima (2009), são muitos os desafios enfrentados por esses empreendimentos associativos, dentre os quais se destaca a baixa produtividade, com efeitos diretos na pequena arrecadação dos associados, e a ausência de recursos para melhoria do processo. Indiretamente, diminuem também os benefícios ambientais da reciclagem, colocando-se em questão sua viabilidade como alternativa às outras destinações dos resíduos sólidos, como o aterramento ou a incineração. Aumentar a eficiência dos processos relacionados com o tratamento de RSU, desde a coleta até a reciclagem, reduzindo custos de modo que viabilize a universalização da coleta seletiva, é uma questão estratégica para se manter a reciclagem como a principal alternativa para a destinação final dos resíduos sólidos a longo prazo. Reciclagem é tratada neste trabalho como um conjunto de técnicas de transformação dos RSU por alteração química, biológica ou mecânica, que tem por finalidade o retorno da matéria-prima ao ciclo de produção.

Muitos estudos têm sido desenvolvidos com pesquisas e ações visando à eficiente gestão de RSU (SILVA; COSTA, 2005; RIBEIRO; MACHADO; BARRA, 2005, CALDEIRA; REZENDE; HELLER, 2009); entretanto a abrangência do tema e sua importância socioeconômica e ambiental faz com que o caminho para implementação dessas pesquisas ainda seja longo, necessitando-se de investimentos por parte dos organismos públicos e privados para serem efetivamente introduzidas nas organizações e indústrias.

Nesse contexto, este trabalho teve por objetivo a caracterização e avaliação, por meio de mapeamento de processos, das atividades envolvidas na separação de resíduos sólidos urbanos (RSU) em uma Associação de Catadores Itajubenses de Material Reciclável (ACIMAR), em Itajubá, Minas Gerais. No contexto de gerenciamento de processos, são várias as atividades envolvidas, desde a geração dos resíduos sólidos, passando pela coleta, beneficiamento até a sua destinação final. É importante a compreensão do processo, todas as suas etapas e a identificação dos principais gargalos para sua melhoria, uma vez que representa a chave para o sucesso em qualquer negócio. Uma organização é tão efetiva quanto os seus processos, os quais são responsáveis pelo que será ofertado ao cliente, pois a falta de eficiência de um processo resulta em maior custo agregado ao produto final. No caso deste estudo, para a associação de catadores de Itajubá, o que está em questão são os processos envolvidos no beneficiamento dos resíduos sólidos (triagem, prensagem e enfardamento) e tem-se como produto final o material enfardado, pronto para ser vendido para as empresas que fazem a reciclagem.

Primeiramente, foi dada especial atenção à revisão da literatura para a caracterização do problema da coleta seletiva no Brasil e a contextualização de mapeamento de processos, mais especificamente as técnicas de avaliação de processos que possam ser aplicados ao problema em questão. $\mathrm{O}$ estudo possibilitou um levantamento primário de dados por meio de observação, entrevista e questionário para posterior mapeamento do processo de separação dos materiais, bem como a identificação dos principais gargalos para a melhoria do processo de coleta seletiva da associação estudada.

\section{A cadeia produtiva no tratamento de resíduos sólidos urbanos}

A coleta seletiva tem um papel fundamental na adequada destinação dos resíduos sólidos urbanos, na geração de emprego e renda e no desenvolvimento de empresas recicladoras. Para aumentar o volume de material coletado e triado, o incentivo às associações e cooperativas de coletores de rua é de fundamental importância, pois os coletores de rua são os responsáveis pela maior parcela de material recuperado e transformado em matéria-prima para as indústrias recicladoras em todo o país.

Sob o aspecto gerencial, Ulbanere (1996) informa que, geralmente, as usinas brasileiras de tratamento de resíduos sólidos operam com ausência de métodos e técnicas de controle operacional e financeiro. Muitas vezes, a falta de qualidade dos produtos - com presença de impurezas nos materiais recicláveis, contaminação e fragmentos de vidros e plásticos no composto e o elevado percentual de rejeitos gerados - é um fator que colabora para o descrédito desse tipo de sistema de tratamento de RSU. Apesar desses problemas, segundo D'Almeida e Vilhena (2000), uma usina de triagem e compostagem, quando bem operada, 
permite diminuição de 50\%, em média, do volume de resíduos sólidos que seria destinado aos aterros, permitindo, com isso, redução de custos dos serviços e do aumento da vida útil dos aterros sanitários.

As pessoas que vivem de coletar RSU podem ser classificadas, de acordo com Maccarini e Hernández (2007), em três classes básicas: o catador propriamente dito, que vive nos lixões, coletando RSU para posteriormente vendê-los para intermediários ou atravessadores (sucateiros). Existem aqueles que catam nas ruas com seus carrinhos, carroças ou outros veículos, os quais são muitas vezes chamados de carrinheiros, comercializando seus materiais com sucateiros. Por último, há aqueles que trabalham em centros de triagem de materiais recicláveis, frequentemente vinculados a alguma cooperativa ou associação, chamados de trabalhadores coletores ou catadores de materiais recicláveis.

A sustentabilidade dessa cadeia produtiva é mantida quando a coleta seletiva diminui o volume de resíduos sólidos que vai para os aterros sanitários, ou quando os RSU são encaminhados para centrais de triagem, mantidas por cooperativas de catadores, que têm um trabalho mais digno do que vasculhar lixos pelas ruas ou em lixões.

Entretanto, um dos desafios da construção do desenvolvimento sustentável é criar instrumentos de mensuração capazes de prover informações que facilitem a avaliação do grau de sustentabilidade das sociedades, monitorem as tendências de seu desenvolvimento e auxiliem na definição de metas de melhoria (POLAZ; TEIXEIRA, 2009). Por se tratar de organizações com fins lucrativos, as associações de catadores necessitam de uma estrutura capaz de gerir com eficiencia todas as etapas do processo e, assim, se tornarem um empreendimento sustentável.

Parreira, Oliveira e Lima (2009) comentam que a baixa produtividade nos empreendimentos associativos de reciclagem tem um efeito direto sobre as arrecadações das associações, implicando na baixa remuneração dos catadores e em dificuldades para fazer investimentos de melhorias no processo. Mais indiretamente, a baixa produtividade restringe a ampliação da coleta seletiva e, consequentemente, minimiza os benefícios potenciais da reciclagem para o meio ambiente. O faturamento das associações de catadores depende quase exclusivamente da comercialização dos materiais. Portanto, a baixa produtividade desses empreendimentos reflete diretamente na renda dos associados, o que, por sua vez, influencia a "motivação" para o trabalho e é também fonte conflitos e indisciplinas.

De acordo com Tchobanoglous (1977 apud CUNHA; CAIXETA FILHO, 2002), as atividades gerenciais relacionadas com os RSU podem ser agrupadas em seis elementos funcionais. A etapa de geração de resíduos depende da quantidade de resíduos produzida pela população, variando sazonalmente de acordo com época do ano, classe econômica e outros fatores. Em seguida, o acondicionamento é a primeira etapa do processo de remoção de RSU e utilizam-se vasilhames para acomodá-los. Após essa etapa, inicia-se a coleta, que consiste na saída do caminhão de sua garagem até seu retorno, depois de passar por toda a extensão por onde a coleta é realizada. O transbordo é uma etapa intermediária entre a coleta e a separação, na qual os caminhões de coleta depositam o material coletado em veículos com maior capacidade, que levam os RSU até o depósito. Processamento e recuperação é a etapa na qual é decidido o que será feito com o material coletado, podendo ser um processamento definitivo, como no caso da incineração, ou reúso, no caso da reciclagem. Por fim, a etapa de disposição final consiste no confinamento dos resíduos sólidos, como aterros sanitários. Em se tratando de destinação final, os resíduos sólidos passam pelo processo de reciclagem ou compostagem, são transformados em matéria-prima e retornam à cadeia produtiva.

Portanto, são vários os processos envolvidos desde a geração dos resíduos sólidos até seu destino final. Já para as associações de catadores, a maior importância é dada aos processos de beneficiamento dos RSU, pois são os que fazem parte da estrutura de produção na organização. Dentro dessa cadeia, o processo produtivo das associações consiste na coleta dos materiais, distribuição nos boxes, triagem, prensagem e amarração dos fardos, armazenagem e comercialização. Para que se colham bons frutos, uma organização deve gerir seus processos de forma organizada, utilizar técnicas para observar os gargalos existentes e buscar a melhoria da produtividade com análises frequentes sobre a existência de atividades que não agregam valor e que poderiam ser eliminadas, simplificadas ou combinadas.

O gargalo pode estar situado em qualquer elo da cadeia produtiva e ser consequência de causas materiais, como baixa qualidade dos insumos de produção e capacidade de equipamentos, de causas organizacionais, tal como estrutura organizacional, formas de organização do trabalho, ou ainda de procedimentos adotados ou motivacionais, como, por exemplo, salários e esforço despendido (PARREIRA; OLIVEIRA; LIMA, 2009).

\section{A técnica de mapeamento de processos}

Uma das primeiras etapas para a avaliação de processos é entender como eles são classificados. De acordo com Candido, Silva e Zuhlke (2008), os processos podem ser hierarquizados como:

a) macroprocesso: é a identidade da gerência no organograma geral, ou seja, é o nome pelo qual a unidade é conhecida;

b) processo: baseado no conceito de gestão de processos, pode ser divido em processo de realização (essência do funcionamento da gerência, ou seja, o motivo pelo qual os clientes a acionam), processo de apoio (garantem todos os subsídios necessários para o desenvolvimento do processo de realização) e processo de gestão (agrupam-se diretrizes relacionadas à gestão de pessoas e da unidade, segundo as normas coorporativas);

c) subprocesso: agrupamento das atividades de assuntos comuns dentro de um processo;

d) atividade: sequências operacionais representadas em forma de fluxogramas.

Para Damelio (1996), a análise dos processos com o uso de mapas ajuda a melhorar a satisfação dos clientes com a identificação de ações 
para reduzir o ciclo de produção, eliminar defeitos, reduzir custos, eliminar passos que não agregam valor e incrementar a produtividade.

Várias técnicas são utilizadas para se efetuar o mapeamento de processos, como: blueprint, que representa todas as transações em um processo de prestação de serviços, no qual uma "linha de visibilidade" divide as atividades de contato direto e indireto com o cliente; fluxograma, que é uma representação, por meio de símbolos padronizados, dos processos analisados; mapofluxograma, que consiste em um fluxograma disposto sobre a planta do local onde o processo é desenvolvido; UML, que é um fluxograma com ênfase temporal de alguma atividade; entre outros (LEAL, 2003).

\section{Metodologia}

O trabalho utiliza métodos qualitativos por meio da pesquisa bibliográfica e estudo de caso. O levantamento de dados contou com observação, entrevista e questionário, possibilitando o mapeamento dos processos, desde a escala macro até a mais detalhada.

Dentre as técnicas disponíveis para o mapeamento, foram utilizados o mapa de processo e o mapofluxograma. O primeiro foi empregado para representar os processos correlacionados e o segundo, para verificar se há cruzamentos de fluxos desnecessários no galpão da ACIMAR. Independentemente da técnica utilizada, o procedimento para realizar o mapeamento de processo segue, normalmente, as seguintes etapas (BIAZZO, 2000):

a) definição das fronteiras e dos clientes do processo, dos principais inputs e outputs (SIPOC) e dos atores envolvidos no fluxo de trabalho;

b) entrevistas com os responsáveis pelas várias atividades dentro do processo e estudo dos documentos disponíveis, a fim de coletar informações suficientes para reprodução do processo no mapeamento;

c) criação do mapa do processo com base na informação adquirida e revisão passo a passo do mapeamento.

A ferramenta SIPOC (Supplier, Input, Process, Output, Customer), segundo Martinhão Filho e Souza (2006), é utilizada para demonstrar claramente as entradas e saídas do processo, seus fornecedores e clientes. De acordo com Mello et al. (2002), fornecedor é aquele que propicia as entradas necessárias, podendo ser interno ou externo; entrada é o que será transformado na execução do processo; processo é a representação esquemática da sequência das atividades que levam a um resultado esperado; saída é o produto ou serviço como solicitado pelo cliente; cliente é quem recebe o produto ou serviço.

Depois de feitas as entrevistas e levantados os dados pertinentes, efetua-se a criação do mapa do processo. De acordo com Batista et al. (2006), para a construção de um fluxograma ou mapa de processo, é preciso que haja uma sequência lógica das atividades produtivas constituintes do processo. A sequência do processo deve ser apresentada listando-se os símbolos identificadores segundo a ordem de ocorrência e ligando-os por segmentos de reta, que representam o fluxo do item. Esse gráfico tem início com a entrada dos insumos na empresa e segue em cada passo como transportes, armazenamentos, inspeções, montagens, até que se tornem um produto acabado ou parte de um subconjunto, registrando-se o andamento do processo por um ou mais departamentos.

O mapofluxograma foi utilizado com o objetivo de verificar o congestionamento de fluxo dentro das atividades realizadas no galpão. Essa técnica de mapeamento representa as atividades do processo na área em que as mesmas são realizadas (BARNES, 1982), por meio de uma simbologia padronizada pela American Society of Mechanical Engenieers (ASME). Portanto, o mapeamento provê uma estrutura para que processos complexos possam ser avaliados de forma simples, possibilitando a visualização do processo completo e as possíveis mudanças que podem provocar grandes impactos, além de áreas e etapas que não agregam valor (LEAL, 2003).

\section{Objeto de estudo}

O município de Itajubá está situado na região Sul do Estado de Minas Gerais, a 418 km da capital, localizado às margens do rio Sapucaí, na Serra da Mantiqueira. A cidade de Itajubá pode ser considerada uma típica cidade média brasileira, com aproximadamente 100.000 habitantes e densidade populacional de 402,7 habitantes/ $\mathrm{km}^{2}$. Possui uma população predominantemente urbana, com 93\% dos habitantes vivendo em área urbana e apenas $8 \%$ habitando a zona rural, com forte atração agroindustrial e caráter tecnológico, além de possuir uma universidade pública (OLIVEIRA; LIMA; LIMA, 2009).

No município, um dos responsáveis pela coleta seletiva é a ACIMAR. A associação possui atualmente 25 catadores associados, sendo que as atividades da ACIMAR trazem benefício direto a cerca de 100 pessoas (catadores e seus familiares) e benefício indireto a cerca de 25.000 pessoas (número de habitantes dos bairros onde é feita a coleta seletiva). A prefeitura fornece todas as condições necessárias para o desenvolvimento das atividades de coleta seletiva, tais como o depósito (galpão de atividades), equipamentos (prensa, empilhadeira, carrinhos, balança, computador, telefone), transporte, funcionário técnico-administrativo, motorista etc. A associação conta com um caminhão carroceria de madeira, adaptado com gaiola, com capacidade de $12 \mathrm{~m}^{3}$. No galpão são feitas a armazenagem do material, a triagem, a prensagem, a pesagem e as atividades administrativas. Para que a coleta ocorra, a população deve separar os resíduos sólidos secos dos úmidos, sendo os secos levados ao galpão da associação para ser realizada a triagem. Esse RSU seco consiste em: papel, plástico, metais, papelão, vidros e materiais eletrônicos. Além disso, também é coletado óleo de cozinha usado que não é mais utilizado na preparação de alimentos.

A Figura 1 apresenta as porcentagens de RSU coletados pela ACIMAR, referentes ao peso do material, nos meses de janeiro, fevereiro e março de 2009. 
É notável que a participação do papelão é bastante significativa, uma vez que representa o material que possui o maior peso para venda. Entretanto, quando consideramos o volume coletado, os materiais plásticos possuem uma representatividade maior, sendo compostos por PET verde, PET transparente, PET óleo, Tetra park, PAD branco, PAD colorido e plásticos em geral, ocupando um grande espaço nas instalações da ACIMAR.

\section{Caracterização dos processos}

Primeiramente, além de observação, foi aplicado aos associados um questionário a fim de delimitar claramente os processos, entradas, saídas, fornecedores e clientes, sob uma visão macro de tudo o que é desempenhado no galpão, a partir do momento em que chegam os resíduos coletados. As respostas obtidas com a entrevista e questionário possibilitaram a elaboração de um SIPOC, conforme descrito na Tabela 1. Observa-se por meio do SIPOC que a ACIMAR, como uma organização que trabalha com o setor de venda de materiais recicláveis, possui em sua estrutura organizacional quatro principais processos responsáveis pela produtividade da associação. O SIPOC possibilitou a visualização clara dos fornecedores e clientes envolvidos em todas as etapas dos serviços realizados.

O processo de triagem recebe do setor de coleta o material coletado na rua e o que foi recebido por doações; o setor de triagem fornece ao processo de triagem a mão de obra necessária para a realização dessa tarefa, que tem como saída o material separado de acordo com sua classificação, que por sua vez, tem como cliente final o setor de pesagem. A triagem é uma etapa importante do processo, pois é uma das que mais agrega valor ao produto

No setor de pesagem, o fornecedor de mão de obra e equipamento é a própria pesagem e o setor de triagem que fornece o material separado, tendo como saída o material enfardado que segue para o setor de prensagem e enfardamento. O terceiro processo tem como fornecedores o setor de pesagem, que fornece o material já pesado, e o setor de prensagem e enfardamento que, depois de realizar seu processo, tem como resultado o material enfardado que é direcionado ao setor de expedição que, por sua vez, fornece a mão de obra e o caminhão para que o material advindo do setor de prensagem e enfardamento seja encaminhado ao veículo cedido pelo cliente final da associação. Os clientes finais da ACIMAR são caracterizados como pequenas empresas de RSU situadas no sul do Estado de Minas Gerais e no Estado de São Paulo, que transformam essa matéria-prima comprada da associação em produtos com maior valor agregado.

Vale ressaltar que os atores desses processos não são necessariamente distintos, podendo atuar em várias etapas, com exceção da pesagem e prensagem, nas quais os equipamentos envolvidos só podem ser operados por pessoas específicas. No caso da prensa trata-se de um associado capacitado e, no caso da balança, tem-se um funcionário administrativo fornecido pela prefeitura da cidade. A partir da visão macro dos processos, realizou-se um segundo questionário

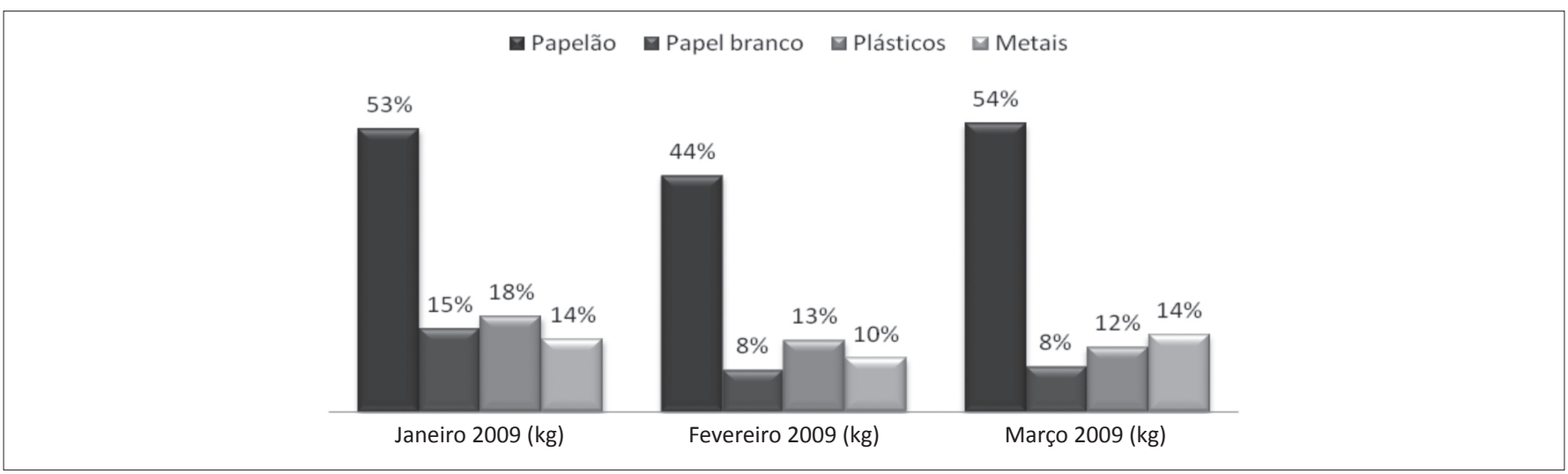

Figura 1 - Porcentagens de resíduos sólidos urbanos coletados pela Associação de Catadordes Itajubenses de Material Reciclável (ACIMAR).

Tabela 1 - SIPOC dos processos realizados no galpão da associação

\begin{tabular}{|c|c|c|c|c|}
\hline Supplier & Input & Process & Output & Customer \\
\hline $\begin{array}{l}\text { Setor de coleta } \\
\text { Setor de triagem }\end{array}$ & $\begin{array}{l}\text { Material coletado na } \\
\text { rua e doações } \\
\text { Mão de obra }\end{array}$ & Triagem & Material separado & Setor de pesagem \\
\hline $\begin{array}{l}\text { Setor de triagem } \\
\text { Setor de pesagem }\end{array}$ & $\begin{array}{l}\text { Material separado } \\
\text { Mão de obra } \\
\text { Balança }\end{array}$ & Pesagem & Material pesado & $\begin{array}{l}\text { Setor de prensagem } \\
\text { e enfardamento }\end{array}$ \\
\hline $\begin{array}{l}\text { Setor de pesagem } \\
\text { Setor de prensagem }\end{array}$ & $\begin{array}{l}\text { Material pesado } \\
\text { Mão de obra } \\
\text { Prensa }\end{array}$ & $\begin{array}{l}\text { Prensagem e } \\
\text { enfardamento }\end{array}$ & Material enfardado & Setor de expedição \\
\hline $\begin{array}{l}\text { Setor de prensagem e } \\
\text { enfardamento } \\
\text { Setor de expedição }\end{array}$ & $\begin{array}{l}\text { Material enfardado } \\
\text { Mão de obra } \\
\text { Caminhão }\end{array}$ & Expedição & $\begin{array}{l}\text { Material enfardado } \\
\text { no caminhão }\end{array}$ & Cliente final \\
\hline
\end{tabular}


possibilitando a caracterização e o detalhamento de todas as atividades envolvidas no processo de seleção dos resíduos coletados. Os processos e suas respectivas atividades são descritos na Tabela 2.

Verifica-se que dentro do macroprocesso de seleção de materiais há 4 processos, 7 subprocessos e 16 atividades específicas. Primeiramente, ao chegar ao galpão, o caminhão com os catadores e seus respectivos bags deposita essas sacolas na entrada do galpão e, em seguida, cada catador com seu bag procura na área do galpão um local que permita a realização da triagem dos resíduos coletados. $\mathrm{Na}$ etapa da triagem, todo o material coletado é classificado como: PET verde, PET transparente, PET óleo, Tetra park, PAD branco, PAD colorido, plásticos em geral, materiais eletrônicos, papelão, papel branco, latas de alumínio, vidros e metais.

Alguns cuidados especiais são tomados durante a etapa de triagem: do papel branco deve-se retirar possíveis espirais, no caso de estar encadernado; do papelão deve-se retirar possíveis plásticos que estejam junto deste; da garrafa PET deve-se retirar a tampa, para que durante a prensagem não se acumule ar dentro da garrafa. Depois de realizada a triagem, cada catador leva todo material triado para a pesagem e, em seguida, armazena cada tipo de resíduo no seu local correspondente no galpão. Em seguida, o responsável por operar a prensa da associação, com o auxílio de um ajudante, inspeciona rapidamente o material, para verificar se, por acaso, há materiais diferentes misturados, enquanto os coloca na prensa. Durante a prensagem, são amarrados arames ao redor do fardo para evitar que este se desfaça durante sua estocagem. Por fim, o material enfardado é estocado no seu local correspondente até a expedição, que ocorre uma vez por mês, quando os clientes retiram o material comprado do galpão. A divisão dos recursos é feita pelo método que os associados chamam de "divisão por produtividade", ou seja, o valor arrecadado é dividido de acordo com a quantidade coletada - quem coletou mais ganha uma parcela maior do que quem coletou menos.

\section{Mapeamento e análise dos resultados}

Com as informações coletadas, foi possível mapear as atividades desenvolvidas. A Figura 2 apresenta o mapa desenvolvido para caracterização e avaliação do processo de seleção de RSU.

O mapa contém sete fluxos de atividades caracterizados pelas atividades desempenhadas e necessárias para cada tipo de material. Os materiais representados no mapa foram classificados em materiais plásticos (MP), papelão (PP), papel branco (PB), latas (L), vidros (V) e metais (M) materiais eletrônicos (ME). Junto ao símbolo que indica transporte, há um código especificando o destino do material e a distância percorrida em centímetros.

Nota-se que as atividades desempenhadas são contabilizadas num total de 63 operações, divididas em: 18 operações, 26 transportes, 9 esperas, 2 inspeções e 9 armazenagens. Entretanto, é importante para a gestão de processos que o maior número de atividades seja classificado como operações, pois estas são as que mais agregam valor ao produto final. Porém, observa-se o grande número de movimentações realizadas no galpão da associação, onde a quantidade de transporte chega a mais de $40 \%$ do total de atividades realizadas. Essa verificação é bastante representativa para a avaliação de processos, uma vez que as operações de movimentação podem ser minimizadas por meio de um estudo detalhado do arranjo físico das instalações e, assim, representar melhorias no fluxo de atividades e aumentar a produtividade da ACIMAR.

Por outro lado, o número de esperas também é significativo (14\% das atividades), indicando a carência de equipamentos e pessoal em operações como pesagem e prensagem. Esse é um problema que reflete a necessidade de melhores condições de trabalho, que pode ser oferecido muitas vezes pelos organismos públicos ou organismos privados que colaboram com as associações, ou por meio do melhor gerenciamento dos processos realizados dentro do galpão.

Tabela 2 - Caracterização do processo de seleção de resíduos sólidos urbanos

\begin{tabular}{|c|c|c|c|}
\hline Macroprocesso & Processos ou etapas & Subprocessos & Atividades \\
\hline \multirow{16}{*}{$\begin{array}{l}\text { Seleção dos } \\
\text { materiais }\end{array}$} & \multirow{3}{*}{ Triagem } & $\begin{array}{c}\text { Depósito do } \\
\text { material coletado }\end{array}$ & Retirar bags do caminhão e depositar no chão do galpão \\
\hline & & \multirow{2}{*}{ Triagem } & Buscar um local para a realização da triagem \\
\hline & & & Separar os resíduos de acordo com a classificação do material \\
\hline & \multirow{5}{*}{ Pesagem } & \multirow{3}{*}{ Pesagem } & Levar material separado para a balança \\
\hline & & & Esperar para pesar \\
\hline & & & Pesar cada tipo de material coletado por cada catador \\
\hline & & \multirow{2}{*}{$\begin{array}{l}\text { Armazenamento } \\
\text { pós-triagem }\end{array}$} & Levar material pesado para seu respectivo local de armazenamento \\
\hline & & & Armazenar cada material no seu local adequado \\
\hline & \multirow{6}{*}{$\begin{array}{l}\text { Prensagem e } \\
\text { enfardamento }\end{array}$} & \multirow{4}{*}{$\begin{array}{l}\text { Prensagem e } \\
\text { enfardamento }\end{array}$} & Inspecionar o material antes de levá-lo à prensa \\
\hline & & & Levar material até a prensa \\
\hline & & & Realizar a prensagem e enfardamento \\
\hline & & & Esperar para armazenar \\
\hline & & \multirow{2}{*}{$\begin{array}{c}\text { Armazenagem } \\
\text { pós-enfardamento }\end{array}$} & Levar fardos para local adequado de armazenamento \\
\hline & & & Armazenar fardos em seus respectivos locais \\
\hline & \multirow{2}{*}{ Expedição } & \multirow{2}{*}{ Expedição } & Levar fardos até o caminhão de expedição \\
\hline & & & Expedição \\
\hline
\end{tabular}




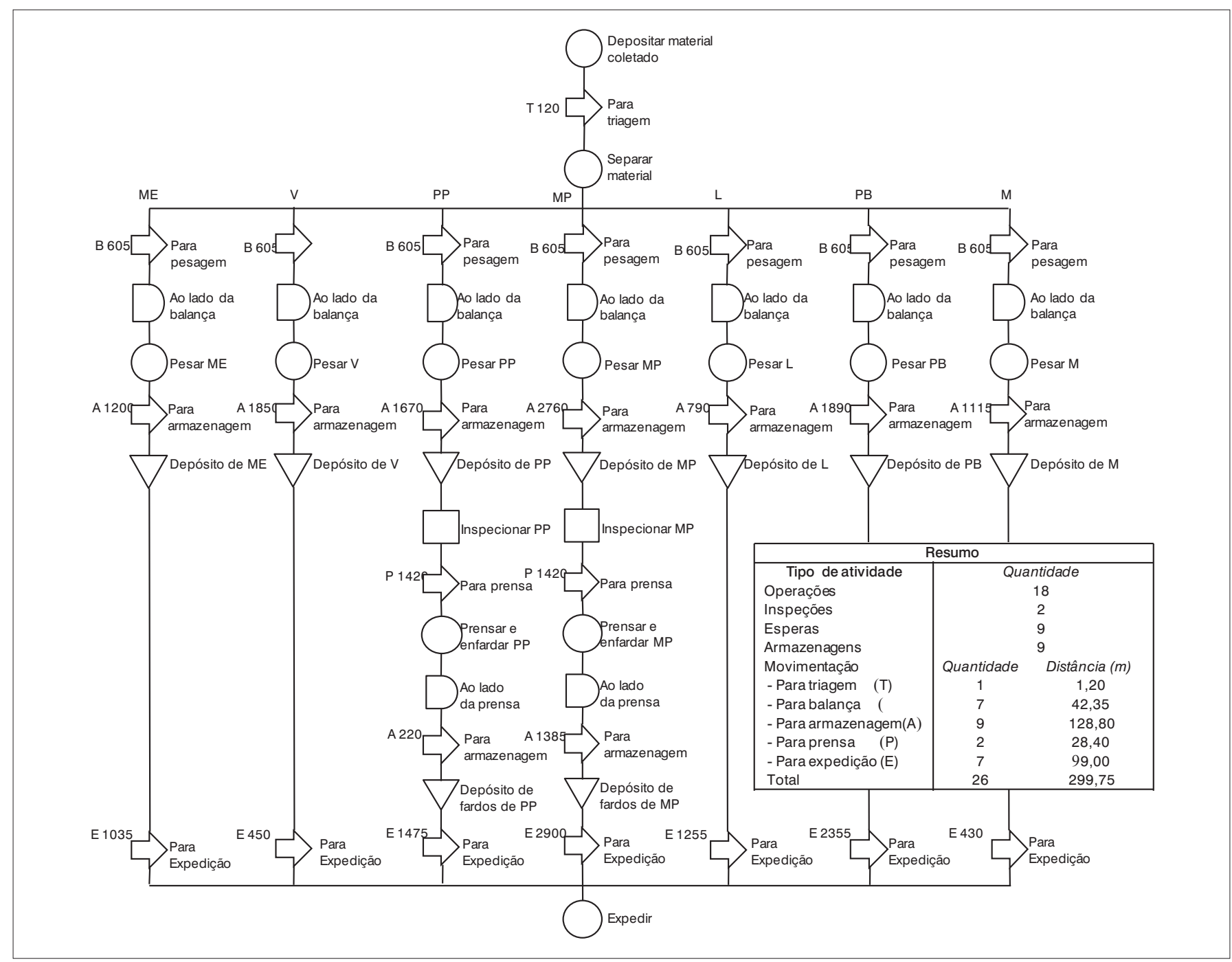

Figura 2 - Mapa do macroprocesso de seleção de resíduos sólidos urbanos da Associação de Catadordes Itajubenses de Material Reciclável (ACIMAR). ME: materiais eletrônicos; V: vidros; PP: papelão; MP: materiais plásticos; L: latas; PB: papel branco; M: metais.

Com o intuito de especificar um pouco mais o processo de seleção, foi realizada uma análise mais detalhada do fluxo de atividades referente à seleção de $\mathrm{MP}$, por se tratar de um material com grande volume coletado pelos catadores e ser bastante representativo com relação a sua comercialização. Esse tipo de material, assim como o PP, caracteriza-se por participar de todas as etapas do processo. A Tabela 3 apresenta as atividades envolvidas na separação de MP, com os respectivos tempos gastos e distâncias percorridas dentro do galpão em cada movimentação. Os tempos determinados por meio de coleta de dados e observação são tempos médios para a realização de cada uma das atividades do processo de seleção de MP.

Os tempos e distâncias observados para as atividades 1 a 6 são característicos de todo o material coletado nos bags, independentemente do seu tipo. Porém, a partir da atividade 7, a distância que se percorre pelo galpão varia de acordo com o tipo de material, uma vez que cada um é armazenado em local diferente. Para as atividades de 9 a 11 (Tabela 3), não foi possível especificar o tempo de cada uma, pois todas são feitas em conjunto e várias vezes, até se obter o resultado final: o fardo. Entretanto, o tempo médio necessário para realizar as três atividades é de 90 minutos.

Considerando-se que os 90 minutos referem-se a um conjunto de atividades, cabe ressaltar que a atividade 3 (separação dos materiais na etapa de triagem) é visivelmente a que mais despende tempo (60 minutos), devido a várias questões, tais como materiais misturados com resíduos úmidos, baixa qualidade do material que muitas vezes precisa ser descartado e o simples fato de ser realizada manualmente. Observa-se ainda que a atividade 15 (levar os fardos para o caminhão) também é significativa com relação ao seu tempo de execução (50 minutos). Esse resultado é o reflexo do arranjo físico atual das instalações da associação, uma vez que os fardos ficam guardados no fundo do galpão e o caminhão que faz a expedição fica estacionado na entrada. A necessidade de atravessar o galpão e, ainda, a presença de materiais que estão no chão do galpão na etapa de triagem, prejudicam a execução de transporte dos fardos para a 
Tabela 3 - Atividades de seleção de materiais plásticos

\begin{tabular}{|c|c|c|c|c|c|}
\hline & $\begin{array}{c}\text { Tempo } \\
\text { (minutos) }\end{array}$ & $\begin{array}{l}\text { Distância } \\
(\mathrm{m})\end{array}$ & Atividade & Processos ou etapas & \multirow{17}{*}{$\begin{array}{c}\text { Seleção dos } \\
\text { materiais }\end{array}$} \\
\hline 1 & 15 & & Depositar os materiais coletados & \multirow{3}{*}{ Triagem } & \\
\hline 2 & 5 & 1,20 & Procurar lugar disponível para realizar a triagem & & \\
\hline 3 & 60 & & Realizar separação dos materiais & & \\
\hline 4 & 5 & 6,05 & Ir para a balança & \multirow{5}{*}{ Pesagem } & \\
\hline 5 & 30 & & Esperar a pesagem & & \\
\hline 6 & 10 & & Realizar pesagem & & \\
\hline 7 & 10 & 27,60 & Ir para locais de armazenagem & & \\
\hline 8 & 5 & & Armazenar material triado & & \\
\hline 9 & 90 & & Inspecionar e aprovar & \multirow{6}{*}{ Prensagem e Enfardamento } & \\
\hline 10 & & 14,20 & Levar material para prensa & & \\
\hline 11 & & & Realizar a prensagem e enfardamento & & \\
\hline 12 & 20 & & Esperar para armazenar & & \\
\hline 13 & 5 & 13,85 & Levar os fardos para armazenamento & & \\
\hline 14 & 10 & & Armazenar fardos & & \\
\hline 15 & 50 & 29 & Levar fardos ao caminhão de expedição & \multirow{2}{*}{ Expedição } & \\
\hline 16 & & & Expedir os fardos & & \\
\hline Total & 315 & 91,90 & & & \\
\hline
\end{tabular}

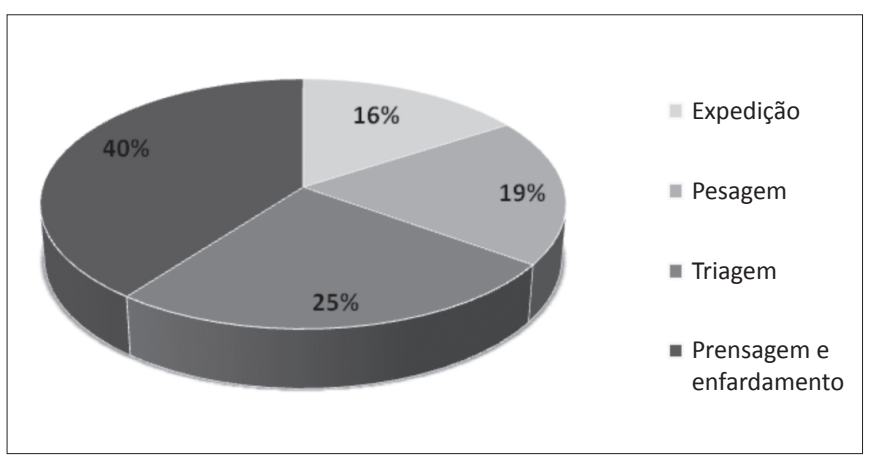

Figura 3 - Porcentagem de tempo gasto nas etapas de seleção de materiais plásticos.

expedição, aumentando o tempo gasto nessa atividade. A Figura 3 mostra a distribuição dos tempos utilizados na realização de cada etapa do processo.

Nota-se que a etapa que mais gasta tempo, dentre as atividades de seleção, é a prensagem e enfardamento. A razão para o elevado tempo despendido na realização dessa etapa está no fato de que ao mesmo tempo em que o operador da prensa pega o material realiza também a inspeção, levando o material para a prensa e diminuindo o seu volume. Entretanto, o operador necessita repetir essa operação várias vezes até que o fardo tenha o volume adequado. Além disso, apenas uma pessoa é responsável pela tarefa de inspeção, transporte e prensagem, limitando a produtividade, pois enquanto é realizada a inspeção e transporte, a única prensa disponível fica ociosa. Assim, o tempo gasto acaba ficando maior quando comparado com a etapa de triagem, que é a segunda operação que mais despende tempo. A triagem é considerada por muitos autores (PARREIRA; OLIVEIRA; LIMA, 2009) como a principal restrição ao aumento de produtividade, pois ainda é baseada exclusivamente no trabalho manual. No entanto, para aumentar a eficiência da triagem, é necessário atuar em todos os elos da cadeia produtiva de materiais reciclados, dadas as inter-relações existentes entre as diversas etapas do processo.

É importante comentar que o tempo que decorre para a finalização de um fardo varia de acordo com o material prensado, sendo o papelão o de mais fácil prensagem e as garrafas PET e PAD as mais difíceis, devido ao acúmulo de ar no seu interior. A frequência com que cada tipo de material é prensado e enfardado varia de acordo com o volume de material coletado; assim, é prensado primeiro o material que tiver maior volume coletado. Mais uma vez constatase que, além das movimentações, a falta de equipamentos (balança e prensa) colabora significativamente para o aumento do tempo de ciclo, sendo gargalo do processo.

A fim de melhor visualizar a movimentação de pessoas e materiais dentro do galpão, a Figura 4 apresenta o mapofluxograma das instalações do galpão da associação para o fluxo de atividades relacionadas com os MP. Os números das atividades visualizados no mapofluxograma correspondem às atividades descritas na Tabela 3.

O mapofluxograma desenvolvido possibilitou a visualização da disposição espacial das movimentações que ocorrem dentro do galpão durante o processo de seleção dos MP. O local é dividido em pequenas baias, como são chamados popularmente os espaços reservados para a armazenagem do material separado. As linhas cheias representam espaços delimitados por estruturas físicas como paredes ou madeiras no caso das baias; já as linhas tracejadas representam locais onde materiais são depositados sem qualquer especificação ou demarcação dessas áreas. Ainda, logo na entrada do galpão, há um espaço maior reservado para a colocação dos bags com material que chega da rua após a coleta.

Verifica-se um grande cruzamento de movimentação dentro do galpão, principalmente na sua região central. Em se tratando do arranjo físico das instalações, o mapofluxograma possibilitou algumas 


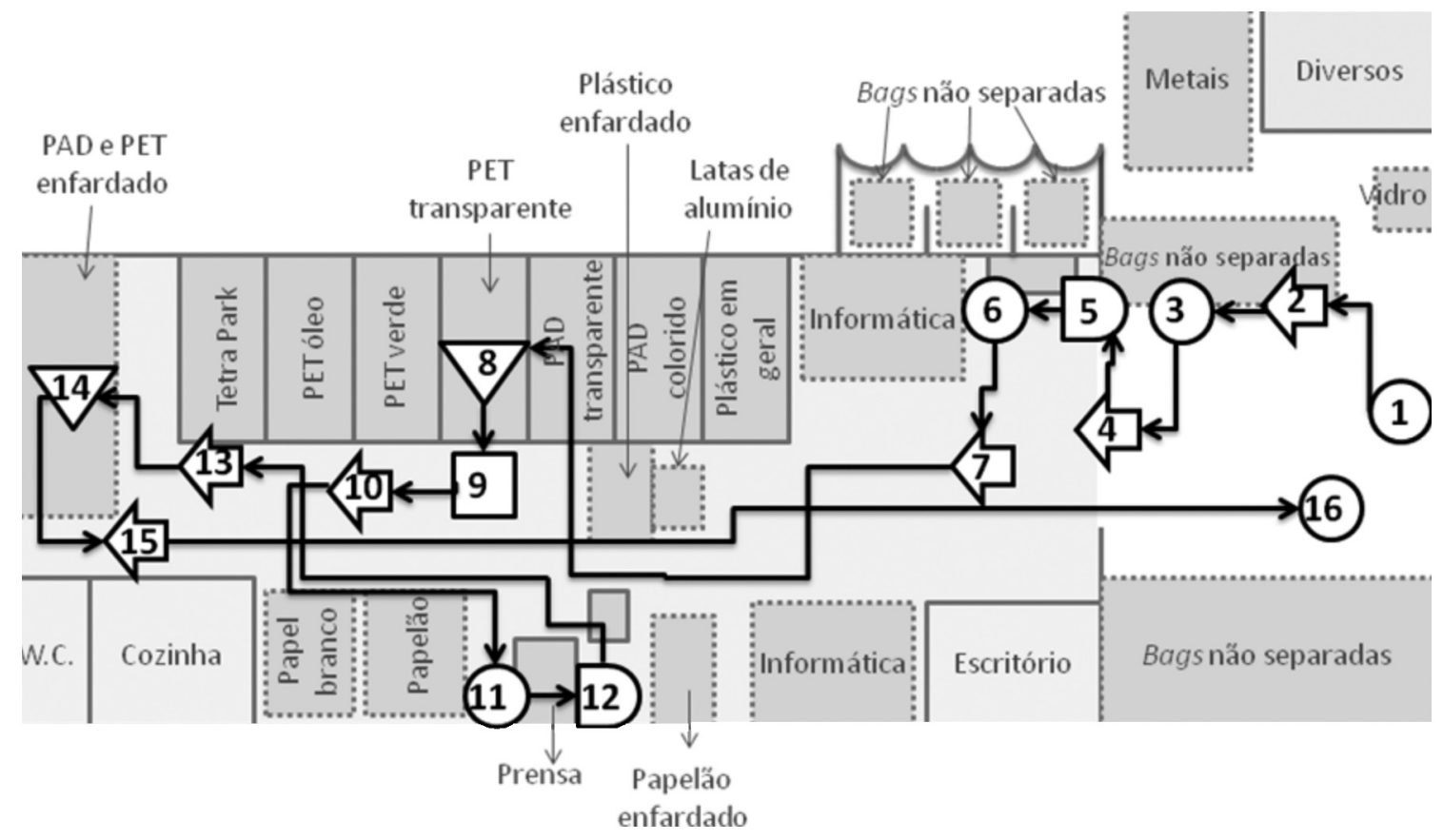

Figura 4 - Mapofluxograma do processo de seleção de materiais plásticos.

observações como, por exemplo, a armazenagem dos materiais enfardados fica no lado oposto do local onde é feita a expedição, indicando a necessidade de se percorrer toda a extensão do galpão (29 m) para realizar a última operação (atividade 16). Da mesma forma, a prensagem (atividade 11) deveria estar localizada junto à armazenagem do material enfardado (atividade 14), pois são atividades sucessivas e, dessa forma, se evitaria ter que percorrer 13,85 m da extensão do galpão com o material prensado. Não é a disposição mais satisfatória, pois gasta muito tempo e esforço por parte dos trabalhadores. Por outro lado, os bags são despejados logo na entrada do galpão (atividade 1), no mesmo espaço em que é feita a expedição (atividade 16). Mais uma vez, têm-se o cruzamento de fluxo de atividades tornando a execução das etapas do processo bastante exaustiva.

\section{Conclusões}

O mapeamento de processos como ferramenta gerencial possibilitou a visualização dos processos relacionados com o tratamento de RSU, desde a escala macro até a mais detalhada, assim como o relacionamento entre as atividades envolvidas. Com essas diferentes escalas de visão sobre o processo, as análises sobre a existência de atividades que não agregam valor ficam facilitadas e, assim, atividades que poderiam ser eliminadas, simplificadas ou combinadas ficaram mais visíveis para a gerência de produção da associação.

Apresentaram bons resultados para a caracterização dos processos de seleção dos resíduos que ocorrem no galpão da ACIMAR as técnicas SIPOC, o mapa de processo e o mapofluxograma.
Assim, ao se efetuarem as análises dos mapas desenvolvidos, constatou-se que o macroprocesso de seleção dos materiais apresenta fortes pontos a serem melhorados. Primeiramente, a disposição das máquinas, baias e ausência de limites para diversos locais de armazenagem de materiais ocasionam movimentações com elevadas distâncias percorridas, chegando-se até mesmo a atravessar toda a extensão do galpão, como no caso do transporte para o caminhão de expedição. Essas grandes movimentações também interferem negativamente no tempo total despendido para a realização das etapas envolvidas no processo.

A carência por mais equipamentos, principalmente balança e prensa, resulta em um gargalo na produção de fardos, uma vez que, por haver apenas uma prensa, todo material triado fica armazenado até que haja quantidade suficiente e disponibilidade do equipamento para a prensagem. Por outro lado, a triagem também é uma etapa importante do processo, pois é uma das que mais agrega valor ao produto. O trabalho é todo manual e várias são as pessoas envolvidas, as quais, na maioria das vezes, possuem ritmos diferentes de trabalho, o que gera outro gargalo de produtividade para a associação.

\section{Agradecimentos}

Os autores agradecem ao Conselho Nacional de Desenvolvimento Científico e Tecnológico (CNPq) e à Fundação de Amparo à Pesquisa do Estado de Minas Gerais (FAPEMIG), pelo apoio financeiro concedido a diversos projetos que subsidiaram o desenvolvimento deste trabalho. 


\section{Referências}

ASSOCIAÇÃO BRASILEIRA DE EMPRESAS DE LIMPEZA PÚBLICA E RESÍDUOS ESPACIAIS (ABRELPE). Panorama dos Resíduos Sólidos no Brasil, 2007. 2007. Disponível em: <http://www.abrelpe.org.br/noticia_ destaque_panorama.php> Acesso em: dez. 2008.

BARNES, R.M. Estudo de movimentos e de tempos: projeto e medida do trabalho. 6. ed. São Paulo: Edgard Blücher, 1982.

BATISTA, G. R. et al. Análise do processo produtivo: um estudo comparativo dos recursos esquemáticos. In: ENCONTRO NACIONAL DE ENGENHARIA DE PRODUÇÃO, 26, Fortaleza, CE, 2006.

BIAZZO, S. Approaches to business process analysis: a review. Business Process Management Journal, v. 6, n. 2, p. 99-112, 2000

CALDEIRA, M.M.; REZENDE, S.; HELLER, L. Estudo dos determinantes da coleta de resíduos sólidos urbanos em Minas Gerais. Revista Engenharia Sanitária e Ambiental, v. 14, n. 3, p. 391-400, 2009.

CANDIDO, R.M.; SILVA, M.T.F.M.; ZUHLKE, R.F. Implantação de gestão por processos: estudo de caso numa gerência de um centro de pesquisas. In: ENCONTRO NACIONAL DE ENGENHARIA DE PRODUÇÃO, 28, Rio de Janeiro, RJ, 2008.

CUNHA, V.; CAIXETA FILHO, J.V. Gerenciamento da coleta de resíduos sólidos urbanos: estruturação e aplicação de modelo não-linear de programação por metas. Gestão \& Produção, v. 9, n. 2, p. 143-161, 2002.

D'ALMEIDA, M.L.O.; VILHENA, A. Lixo municipal: manual de gerenciamento integrado. 2. ed. São Paulo: IPT/CEMPRE, 2000

DAMELIO, R. The basics of process mapping. New York: Productivity Press, 1996.

HAMMOND A. et al. Resource flows: the material basis of industrial economies. New York: World Resources Institute, 1997.

INSTITUTO BRASILEIRO DE GEOGRAFIA E ESTATÍSTICA (IBGE). Estimativas das Populações dos Municípios em 2008. Disponível em: $<$ http://www.ibge.gov.br/home/presidencia/noticias/noticia_visualiza. php?id_noticia $=1215 \&$ id_pagina $=1>$. Acesso em dez. 2008.

KIPPER, L.M.; MÄHLMANN, C.M. Ações estratégicas sistêmicas visando à integração da cadeia produtiva e de reciclagem de plásticos. Revista Produção On-line, v. 9, n. 4, p. 848-865, 2009.

KRAJEWSKI, L; RITZMAN, L.; MALHOTRA, M. Administração de produção e operações, 8. ed. São Paulo: Pearson, 2009

LEAL, F. Um diagnóstico do processo de atendimento a clientes em uma agência bancária através de mapeamento do processo e simulação computacional. Dissertação (Mestrado em Engenharia de Produção). Universidade Federal de Itajubá, Itajubá, MG, 2003.

MACCARINI, A.C.; HERNÁNDEZ, R.H. Melhoria no processo de triagem de materiais recicláveis a partir da implementação de tecnologias simples. In: Seminário Anual de Ensino, Pesquisa e Extensão, 11. Jornada de Iniciação Científica, 11, 2007, Pato Branco, PR. Anais... Pato Branco: UTFPR, 2007.

MARTINHÃO FILHO, O.; SOUZA, L.G.M. Restrições técnicas associadas a um sistema integrado de gestão: estudo de caso em uma empresa. In: ENCONTRO NACIONAL DE ENGENHARIA DE PRODUÇÃO, 26 Fortaleza, CE, 2006.

MELLO, C.H.P. et al. ISO 9001:2000. Sistema de gestão da qualidade para operações de produção e serviço, São Paulo: Atlas, 2002.

OLIVEIRA, R.L.; LIMA, J.P.; LIMA, R.S. Logística reversa: o caso de uma associação de coleta seletiva de materiais recicláveis em Itajubá - MG. In: ENCONTRO NACIONAL DE ENGENHARIA DE PRODUÇÃO, 29 , Salvador, BA, 2009.

PADUA, J.A. Produção, consumo e sustentabilidade: o Brasil e o contexto planetário. In: Parreira, C.; Alimonda, H., Políticas Públicas Ambientais Latino-americanas, $1^{\text {a }}$ ed., Brasília, 2005, Faculdade Latino-americana de Ciências Sociais (FLACSO), 169-200, 2005.

PARREIRA, G.F.; OLIVEIRA, F.G.; LIMA; F.P.A. O gargalo da reciclagem: determinantes sistêmicos da triagem de materiais recicláveis. In: ENCONTRO NACIONAL DE ENGENHARIA DE PRODUÇÃO, 29 Salvador, BA, 2009

POLAZ, C.N.M.; TEIXEIRA, B.A.N. Indicadores de sustentabilidade para a gestão municipal de resíduos sólidos urbanos: um estudo para São Carlos (SP). Revista Engenharia Sanitária e Ambiental, v. 14, n. 3, p. 411-420, 2009.

RIBEIRO, L.M.P.; MACHADO, R.T.M.; BARRA, G.M.J. A logística na gestão de resíduos sólidos: um estudo de caso em um pequeno município mineiro. In: SIMPÓSIO DE ADMINISTRAÇÃO DA PRODUÇÃO, LOGÍSTICA E OPERAÇÕES INTERNACIONAIS, 8, São Paulo: FGVEAESP, 2005.

RODRIGUES, F. L.; CAVINATTO, V. M. Lixo - De onde vem? Para onde vai? São Paulo: Moderna, 2003.

SATO, M.; SANTOS, J.E. Agenda 21 em sinopse. São Carlos: Programa de Pós-Graduação em Ecologia e Recursos Naturais, Universidade Federal de São Carlos, 1996.

SILVA, A.T.T.; COSTA H.S. Estudo preliminar sobre os resíduos sólidos domiciliares da cidade de Itajubá (MG): caracterização física no período do inverno. In: CONGRESSO BRASILEIRO DE ENGENHARIA SANITÁRIA E AMBIENTAL, 23, Campo Grande, MS, 2005.

ULBANERE, R.C. Análise ambiental de usinas de reciclagem de resíduos sólidos. Revista de Engenharia e Ciências Aplicadas, São Paulo, v. 3, p. $57-74,1996$

VILLELA, C.S.S. Mapeamento de processos como ferramenta de reestruturação e aprendizado organizacional. Dissertação (Mestrado em Engenharia de Produção). Universidade Federal de Santa Catarina, Florianópolis, SC, 2000. 